\section{(2) OPEN ACCESS}

\title{
Primary malignant melanoma of the vagina
}

\author{
Emily Jamaer (10 ,' Zach Liang, ${ }^{2}$ Brendan Stagg ${ }^{3}$
}

'Obstetrics and Gynecology, Flinders Medical Centre, Bedford Park, South Australia, Australia ${ }^{2}$ Obstetrics and Gynecology, Flinders University, Adelaide, South Australia, Australia ${ }^{3}$ Pathology, Flinders Cancer Clinic, Bedford Park, South Australia, Australia

Correspondence to Dr Emily Jamaer; emilyjamaer@gmail.com

Accepted 17 December 2019

Check for updates

(c) BMJ Publishing Group Limited 2020. Re-use permitted under CC BY-NC. No commercial re-use. See rights and permissions. Published by BMJ.

To cite: Jamaer $\mathrm{E}$, Liang $\mathrm{Z}$, Stagg B. BMJ Case Rep

2020:13:e232200.

doi:10.1136/bcr-2019-

232200

\section{SUMMARY}

Primary malignant melanoma of the vagina is a rare gynaecological neoplasm with an aggressive course of disease. Although not many cases have been reported in the literature, its manifestations appear to be fairly consistent. The challenge comes in knowing how to approach this cancer clinically, since information about its staging and treatment is limited. In this report, we present a case of an 84-year-old postmenopausal woman in whom a suspicious vaginal lesion was discovered incidentally during a procedure. Wide local excision was carried out at a later date and histopathology confirmed a malignant melanoma of the vagina contained locally with no radiological finding of distant metastases. No additional treatment was given, and three monthly follow-ups were arranged for this patient. We review the literature and briefly discuss the epidemiology, treatment approaches, prognostic factors and expected outcomes of this rare disease.

\section{BACKGROUND}

Primary vaginal melanoma is an extremely rare gynaecological malignancy comprising less than $0.2 \%$ of all melanomas. ${ }^{1}$ Although far fewer in number, melanoma of the vagina is significantly more aggressive than its cutaneous counterparts, with 5-year survival rates being reported at less than $30 \%$ despite treatment..$^{2-4}$ Importantly, the scarcity of cases both encountered in clinical practice and reported in the literature poses challenges with regards to knowing how to stage and treat this disease.

In this report of a primary vaginal melanoma that we encountered in an 84-year-old postmenopausal woman, we wish not only to highlight some of the issues that were raised during our multidisciplinary team meetings concerning this case, but also to build on and contribute to what is presently a relatively scant field of information relating to this rare neoplasm. This will hopefully guide future efforts in disease characterisation and treatment optimisation for primary vaginal melanomas.

\section{CASE PRESENTATION}

An 84-year-old woman with no medical or family history of malignancy was admitted to the hospital for a below-knee amputation on a background of long-standing arterial disease. It was during the preoperative insertion of an indwelling urinary catheter in the operating theatre when an incidental finding of a vaginal mass was made. The lesion, which measured $3 \times 2 \mathrm{~cm}$, was located on the lateral lower one-third of the vaginal wall and extended to the left side of the vulva; a second smaller lesion of $2 \mathrm{~mm}$ was noted close to the urethral opening. Both lesions were amelanotic, ulcerated, polypoid and bled easily.

Subsequent review by the gynaecology team revealed history of a previous vaginal hysterectomy for menorrhagia, but an unremarkable smear history, no vaginal discharge or local pain and no reports of vaginal blood loss. The upper twothirds of the vagina and the vaginal vault appeared normal, and both parametria and the rectum were free on palpation. There were no palpable inguinal lymph nodes.

\section{INVESTIGATIONS}

The patient chose to undergo wide local excision of the lesion, and this was performed under general anaesthesia. The inguinal nodes were not removed since there were no signs of lymphadenopathy. Surgical microscopy was used for pathological characterisation of the excised lesion.

Histological assessment revealed a melanoma arising from the vaginal mucosa. A precursor lesion was identified with atypical melanocytes exhibiting a lentiginous pattern of growth along the base of the vaginal epithelium (figure 1) and invading the underlying connective tissue (figure 2). The tumour thickness was $8.5 \mathrm{~mm}$, forming an ulcerated polypoid mass (figure 3 ). It was comprised of sheets of epithelioid melanocytes with rounded nuclei, open chromatin and prominent nucleoli (figure 4). The tumour cells contained clumps of brown cytoplasmic pigment consistent with melanin. The presence of an adjacent in situ component along with the morphology of the invasive tumour cells was regarded as diagnostic of malignant melanoma. There was no evidence of vascular or perineural invasion and no features suggestive of regression.

Consequently, a staging CT of the chest, abdomen, pelvis and brain was carried out. No sign of metastatic disease of lymphadenopathy was demonstrated.

\section{TREATMENT}

Due to her cardiac comorbidities, it was decided collectively-by the multidisciplinary oncology team, the patient and her family-that no additional treatment, such as radiotherapy or chemotherapy, would be carried out.

\section{OUTCOME AND FOLLOW-UP}

At the time of this report, the patient was alive and displayed no evidence of disease recurrence or complication. The patient is currently undergoing 


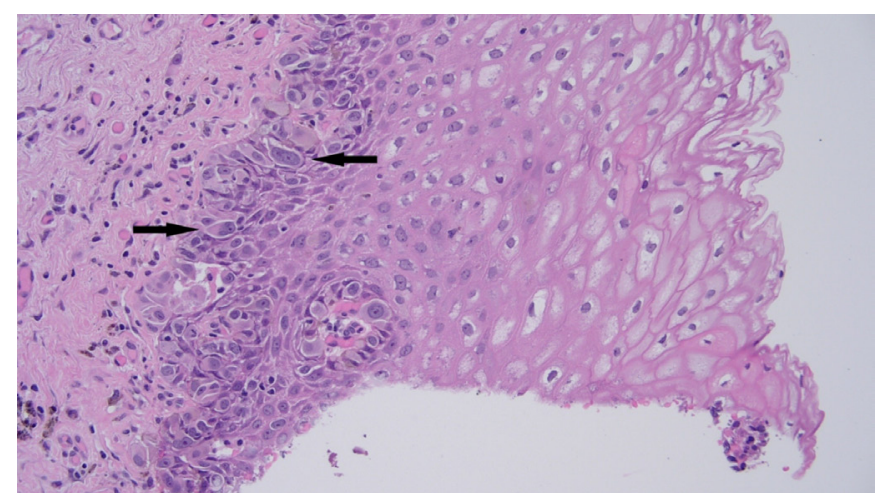

Figure 1 Melanocytes within the basal layer of the squamous epithelium showing cytological atypia with nuclear enlargement, increased nuclear-cytoplasmic ratios, pleomorphism and prominent nucleoli.

three monthly follow-ups and clinical surveillance. The use of topical imiquimod will be considered if signs of local disease recurrence present during the follow-up.

\section{DISCUSSION}

The infrequency of primary vaginal melanoma precludes proper characterisation of this disease, and much therefore remains equivocal with regards to our understanding and clinical approach of this cancer. This is especially true of staging and choice of treatment.

Vaginal melanoma is known to affect mainly postmenopausal women between the ages of 60 and 80, with abnormal vaginal bleeding being the most commonly reported symptom. ${ }^{45}$ Proposed mechanisms of its pathogenesis and etiological factors have implicated everything from genetics, the environment and even to the cellular microenvironment-or interactions between any of these-yet are suppositions at best. ${ }^{67}$ Race or ethnicity does not appear to have a significant influence on the incidence of this cancer. ${ }^{8}$

\section{Diagnosis}

Accurate diagnosis of primary vaginal melanoma is based on a combination of visual inspection and histopathological evaluation. Often, physical examination alone is sufficient to give a good degree of suspicion for a vaginal melanoma, although variations in the appearance of lesions can give rise to misdiagnosis. For instance, while primary melanomas of the vagina

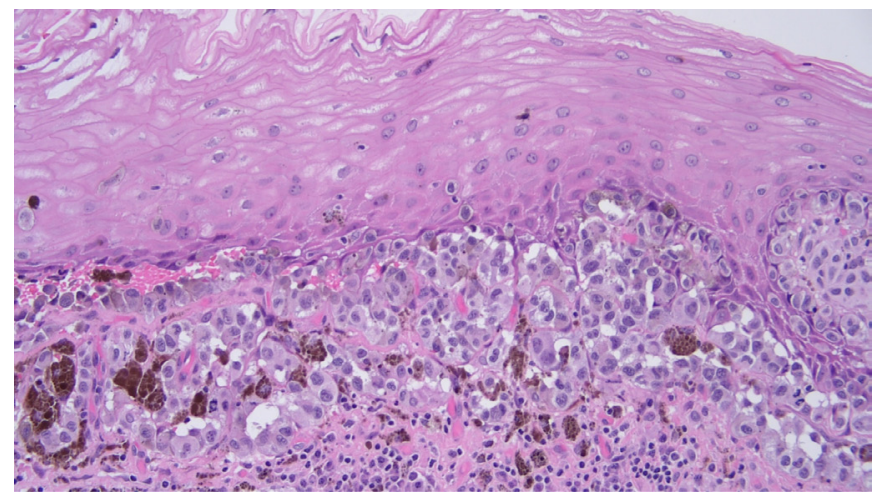

Figure 2 Cells in this slide have similar features to those found in figure 1, but with the brown pigment more conspicuous and the invasiveness more clearly seen.

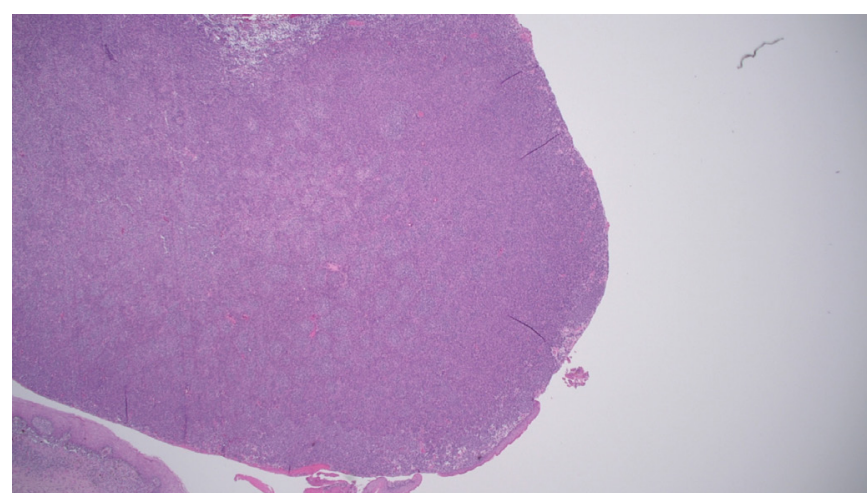

Figure 3 The ulcerated, polypoid mass measuring $8.5 \mathrm{~mm}$ thick; only a small portion of the tumour is lined with squamous epithelium.

are usually found in the lower one-third segment of the anterior vaginal wall, bleed easily on touch and are polypoid in appearance-as was the case with our patient-they are also usually ulcerated and visibly pigmented, in contrast to the two nonulcerated amelanotic lesions found in our patient. ${ }^{3-12}$ As such, clinical assessment ought to be accompanied by histopathological assessment.

\section{Histopathology}

The histopathological findings in our patient are largely consistent with what has been reported in the literature as features commonly observed in primary melanoma of the vagina, namely, and in no particular order: an epithelioid morphology (which is the most common morphology, reported in more than half of the cases $)^{9}$; an in situ component with an overlaying intact epithelium; cytological atypia and mitotic activity. ${ }^{13-15}$ Various markers of immunohistochemical staining have traditionally also been used to provide reliable confirmation of a diagnosis of primary vaginal melanoma, including protein S-100, T311, Mart-1, Melan A, HMB-45, tyrosinase and vimentin. ${ }^{5} 7$ However, staining was not performed on our specimen as we did not see any additional merit in having this information, both for diagnosis and for determining the best course of clinical action to take.

\section{Staging}

Even though primary malignant vaginal melanomas are a known entity, a single best staging protocol for this cancer continues to elude us. This is perhaps due to both the rarity of this disease as

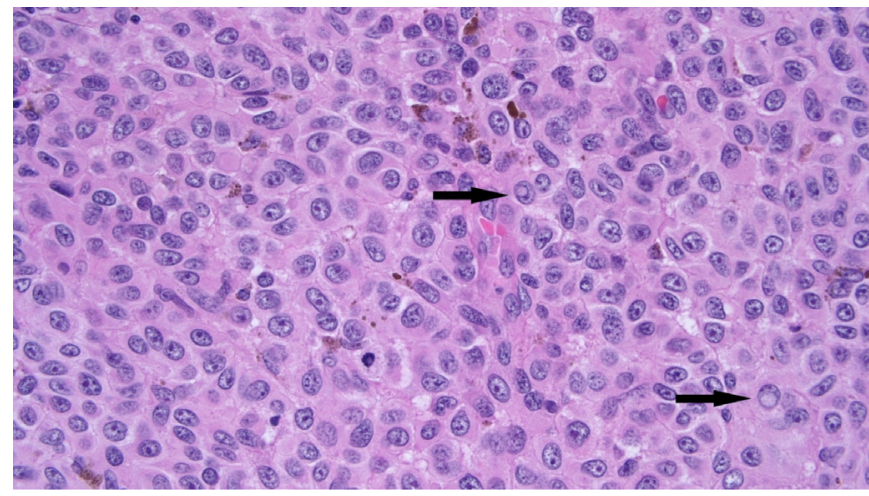

Figure 4 Atypical melanocytes with an epithelioid morphology identified in situ with rounded nuclei, open chromatin and prominent nucleoli. 
well as the fact that it displays traits that make more than one staging system relevant. Historically, as a gynaecological cancer, staging of vaginal melanomas was based on the guidelines for vaginal cancers by the International Federation of Gynecology and Obstetrics (FIGO); however, since melanomas are also primarily a cancer of the skin, where tumour, node, metastases (TNM) staging is widely accepted as the best system, guidelines established by the American Joint Committee on Cancer (AJCC) began to be adopted in conjunction. ${ }^{16}{ }^{17}$ In fact, most reports of primary malignant vaginal melanoma combine the use of both systems. ${ }^{7}$ We wish to note, however, that even though a combination system of staging is the prevailing approach, evidence in the literature appears to favour the AJCC-TNM system as a more reliable predictor of prognosis, and FIGO guidelines might even be dispensable when it comes to primary malignant vaginal melanomas. Of the various aspects of disease, extent of lymph node involvement and tumour size are the only two that have shown an association with outcome, neither of which FIGO incorporates in their system for vaginal cancer. ${ }^{25} 1518$ Furthermore, the AJCC-TNM system was able to show stage-dependent difference in the outcomes where FIGO-based classifications did not. ${ }^{18} 1819$ While Breslow's thickness is one of the most significant predictors of prognosis in vulvar melanomas, this is not true in relation to vaginal melanomas, even though both are mucosal forms of melanoma and are approached very similarly. ${ }^{1520-23}$

\section{Treatment}

Surgery (with or without adjuvant therapy) is associated with the best outcomes and has emerged as the mainstay of treatment for primary malignant vaginal melanoma. ${ }^{23724}$ Surgical approaches for vaginal melanoma can be classified into conservative (including wide local excision and partial vaginectomy) and radical (including hysterectomy, total vaginectomy or vulvectomy, or pelvic exenteration). ${ }^{3}{ }^{15} 25$ In most cases of early disease, wide local excision achieved similar if not better outcomes compared with other treatment options such as radiotherapy or chemotherapy. Lymphadenectomy is not often employed given the low rate of lymph node involvement, and is contraindicated otherwise. ${ }^{326}$ When surgery is not an option due to advanced disease, chemotherapy is used for palliation, with the common chemotherapeutic agents being dacarbazine, temozolomide and paclitaxel. ${ }^{726}$ Radiotherapy is rarely used alone, and is performed more as an adjuvant therapy when non-surgical options are necessary. Importantly, in patients who receive surgery, adjuvant radiation has not been found to offer any advantage in terms of overall survival. ${ }^{26}$ Immunomodulatory drugs such as topical imiquimod (used in actinic keratosis, basal cell carcinoma and genital warts) or monoclonal antibodies (specifically ipilimumab and nivolumab, used in combination) are less conventional means, but have nonetheless demonstrated effectiveness as adjuncts in prolonging survival in the few cases that have been reported. ${ }^{727}$

\section{Expected outcomes}

Studies having assessed 5-year survival rates generally report figures from virtually zero to no higher than roughly $30 \%$, at best. $^{2-428}$ Local recurrence of disease despite surgery of locally contained disease is reported in 30\%-40\% of patients. ${ }^{418} \mathrm{Lymph}$ node involvement, if any, significantly worsened the prognosis of patients. $^{29}$ The reported rate of lymph node involvement or metastases ranges quite widely from as low as $8 \%$ to as high as $50 \% .^{3}{ }^{14}$ Overall, the expected outcome of patients with primary malignant vaginal melanoma is poor. The wide range of numbers reported suggests that there is much we still do not understand with regards to how and whether we can reliably predict outcomes given the clinical pictures we encounter.

\section{Patient's perspective}

Patient's son

When my mother went to the hospital for yet another problem, it was quite a surprise that she was diagnosed with a vaginal lesion. In the beginning it was unclear how the doctors were planning to manage it because they were unsure about the diagnosis. Since the general health of my mother was compromised, the family did not want a radical surgery or long chemotherapy. After considering the advantages and disadvantages, we decided, together with the doctors, to do a wide excision of the lesion.

The most important thing for us was that our mother did not suffer. Due to her comorbidities and mental state, we decided collectively with the multidisciplinary oncology team that no additional treatment, such as radiotherapy or chemotherapy, would be carried out. We know our mother is not in the best condition but hopefully she can stay with us for a bit longer. With this case report, we want to help the doctors to approach this rare problem.

\section{Learning points}

- Primary malignant melanoma of the vagina is a rare gynaecological cancer that affects predominantly postmenopausal women above the age of 60 . While patients are often symptomatic with abnormal vaginal bleeding, incidental discoveries are not uncommon.

- There are variations in the appearance of vaginal melanomas; some can present with a lack of pigmentation, and the possibility of a melanoma should not be overlooked.

- Staging of primary vaginal melanoma currently uses a combination of the American Joint Committee on Cancertumour, node, metastases and International Federation of Obstetrics and Gynecology systems, but can potentially rely on just the former. More comprehensive studies evaluating their applicability and usefulness should be undertaken as the number of cases and reports permit.

- Surgical approaches to treatment are associated with the best outcomes to date. Topical imiquimod is worth exploring further as an adjuvant therapy.

- So far, only lymph node involvement and tumour size have been found to correlate with prognosis of primary vaginal melanoma. However, even with the best clinical picture and the best-known treatment modality (surgery), the expected outcomes are poor.

Contributors EJ conceived of the presented idea and developed the theory and supervised this work. EJ and ZL contributed to the implementation of the research, to the analysis of the results and to the writing of the manuscript. BS provided all the information about pathology and the images. All authors discussed the results and contributed to the final manuscript.

Funding The authors have not declared a specific grant for this research from any funding agency in the public, commercial or not-for-profit sectors.

Competing interests None declared.

Patient consent for publication Parental/guardian consent obtained.

Provenance and peer review Not commissioned; externally peer reviewed.

Open access This is an open access article distributed in accordance with the Creative Commons Attribution Non Commercial (CC BY-NC 4.0) license, which 
permits others to distribute, remix, adapt, build upon this work non-commercially, and license their derivative works on different terms, provided the original work is properly cited and the use is non-commercial. See: http://creativecommons.org/ licenses/by-nc/4.0/.

\section{ORCID iD}

Emily Jamaer http://orcid.org/0000-0002-0392-5178

\section{REFERENCES}

1 Chang AE, Karnell LH, Menck HR. The National cancer data base report on cutaneous and noncutaneous melanoma: a summary of 84,836 cases from the past decade. the American College of surgeons Commission on cancer and the American cancer Society. Cancer 1998;83:1664-78.

2 Kirschner AN, Kidd EA, Dewees T, et al. Treatment approach and outcomes of vaginal melanoma. Int J Gynecol Cancer 2013;23:1484-9.

3 Miner TJ, Delgado R, Zeisler J, et al. Primary vaginal melanoma: a critical analysis of therapy. Ann Surg Oncol 2004;11:34-9.

4 Huang Q, Huang $\mathrm{H}$, Wan T, et al. Clinical outcome of 31 patients with primary malignant melanoma of the vagina. J Gynecol Oncol 2013;24:330-5.

5 Mihajlovic M, Vlajkovic S, Jovanovic P, et al. Primary mucosal melanomas: a comprehensive review. Int J Clin Exp Pathol 2012;5:739-53.

6 Whiteman DC, Pavan WJ, Bastian BC. The melanomas: a synthesis of epidemiological, clinical, histopathological, genetic, and biological aspects, supporting distinct subtypes, causal pathways, and cells of origin. Pigment Cell Melanoma Res 2011;24:879-97.

7 Kalampokas E, Kalampokas T, Damaskos C. Primary vaginal melanoma, a rare and aggressive entity. A case report and review of the literature. In Vivo 2017:31:133-40.

8 Hu D-N, Yu G-P, McCormick SA. Population-Based incidence of vulvar and vaginal melanoma in various races and ethnic groups with comparisons to other site-specific melanomas. Melanoma Res 2010;20:153-8.

9 Androutsopoulos G, Terzakis E, loannidou G, et al. Vaginal primary malignant melanoma: a rare and aggressive tumor. Case Rep Obstet Gynecol 2013;2013:1-6.

10 Xia L, Han D, Yang W, et al. Primary malignant melanoma of the vagina: a retrospective clinicopathologic study of 44 cases. Int J Gynecol Cancer 2014;24:149-55.

11 Baloglu A, Bezircioglu I, Cetinkaya B, et al. Primary malignant melanoma of the vagina. Arch Gynecol Obstet 2009;280:819-22.

12 An J, Wu L, Li B, et al. Primary malignant amelanotic melanoma in the female genital tract: a report of six cases and a review of the literature. Chinese Journal of Clinical Oncology 2008;5:383-6.

13 Allen AC, Spitz S. Malignant melanoma; a clinicopathological analysis of the criteria for diagnosis and prognosis. Cancer 1953;6:1-45.
14 Kühn F, Dieterich M, Klar E, et al. Primary Malignant Vaginal Melanoma - Case Report and Review of the Literature. Geburtshilfe Frauenheilkd 2012:72:740-3.

15 Trimble EL. Melanomas of the vulva and vagina. Oncology 1996;10:1017-23. Discussion 1024

16 FIGO Committee on Gynecologic Oncology. Current FIGO staging for cancer of the vagina, fallopian tube, ovary, and gestational trophoblastic neoplasia. Int J Gynaecol Obstet 2009;105:3-4

17 Edge SB, Compton CC. The American joint Committee on cancer: the 7th edition of the AJCC cancer staging manual and the future of TNM. Ann Surg Oncol 2010;17:1471-4

18 Reid GC, Schmidt RW, Roberts JA, et al. Primary melanoma of the vagina: a clinicopathologic analysis. Obstet Gynecol 1989:74:190-9.

19 Seifried S, Haydu LE, Quinn MJ, et al. Melanoma of the vulva and vagina: principles of staging and their relevance to management based on a clinicopathologic analysis of 85 cases. Ann Surg Oncol 2015;22:1959-66.

20 Phillips GL, Bundy BN, Okagaki T, et al. Malignant melanoma of the vulva treated by radical hemivulvectomy. A prospective study of the gynecologic Oncology Group. Cancer 1994;73:2626-32.

21 Podratz KC, Gaffey TA, Symmonds RE, et al. Melanoma of the vulva: an update. Gynecol Oncol 1983;16:153-68.

22 Scheistrøen M, Tropé C, Koern J, et al. Malignant melanoma of the vulva. evaluation of prognostic factors with emphasis on DNA ploidy in 75 patients. Cancer 1995;75:72-80.

23 Laga AC, Haefner HK, Granter SR. Chapter 8 - Melanocytic Lesions of the Vulva. In: Crum CP, Nucci MR, Howitt BE, eds. Diagnostic gynecologic and obstetric pathology. 3rd edn. Philadelphia: Content Repository Only! 2018: 181-96.

24 Schmidt M, Honig A, Schwab M, et al. Primary vaginal melanoma: a case report and literature review. Eur J Gynaecol Oncol 2008;29:285-8.

25 Piura B. Management of primary melanoma of the female urogenital tract. Lancet Oncol 2008;9:973-81.

26 Leitao MM, Cheng X, Hamilton AL, et al. Gynecologic cancer intergroup (GCIG) consensus review for vulvovaginal melanomas. Int J Gynecol Cancer 2014;24:S117-22

27 Prescott LS, Papadopoulos NE, Euscher ED, et al. Topical treatment of recurrent vaginal melanoma in situ with imiquimod: a case report. Gynecol Oncol Case Rep 2012:2:92-3.

28 Ragnarsson-Olding $B$, Johansson $H$, Rutqvist LE, et al. Malignant melanoma of the vulva and vagina. Trends in incidence, age distribution, and long-term survival among 245 consecutive cases in Sweden 1960-1984. Cancer 1993;71:1893-7.

29 Frumovitz M, Etchepareborda M, Sun CC, et al. Primary malignant melanoma of the vagina. Obstet Gynecol 2010;116:1358-65.

Copyright 2020 BMJ Publishing Group. All rights reserved. For permission to reuse any of this content visit

https://www.bmi.com/company/products-services/rights-and-licensing/permissions/

BMJ Case Report Fellows may re-use this article for personal use and teaching without any further permission.

Become a Fellow of BMJ Case Reports today and you can:

- Submit as many cases as you like

Enjoy fast sympathetic peer review and rapid publication of accepted articles

- Access all the published articles

- Re-use any of the published material for personal use and teaching without further permission

\section{Customer Service}

If you have any further queries about your subscription, please contact our customer services team on +44 (0) 2071111105 or via email at support@bmj.com.

Visit casereports.bmj.com for more articles like this and to become a Fellow 